\title{
Tendinopathies in Athletes: The Role of Eccentric Exercise
}

\author{
Ana Zão* \\ Department of Physical and Rehabilitation Medicine, Porto Hospital Center, Portugal \\ *Corresponding author: Ana Zão, Department of Physical and Rehabilitation Medicine, Porto Hospital Center, Portugal

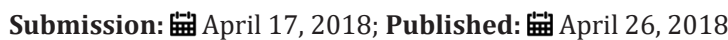

\section{Editorial}

Tendinopathies are one of the most common sport injuries (30\% to $50 \%$ of the athlete's injuries). The tendon are essentially composed of type I collagen fibers and, to a lesser extent, elastic fibers. This type of fibers does not have great elongation capacity, increasing only about $8-10 \%$ in length until they reach the point of failure. Histopathologically, tendinosis is characterized by a degenerative process with increased numbers of fibroblasts, vascular hyperplasia and collagen disorganization [1-3].

Tendinopathy tends to reduce the athlete's performance and may lead to functional impairment and disability. Despite the high prevalence, its treatment can be a challenge. Eccentric exercise (EE) is considered a fundamental therapeutic modality for its potential benefits improving symptoms and functionality. It change tendon microstructure, in part because it allows there organization of collagen fibers. When compared to concentric exercise, EE seems to be more effective because it requires less oxygen consumption, allows for greater power output and less energy expenditure. With EE less muscle activity is required to maintain the same strength and fewer muscle fibers are recruited. Due to the inherent physiological mechanism, the energy requirements are substantially lower, compared to the concentric exercise because the ATP drop and the heat production occur more slowly [4-6].

The Alfred son protocol has been used in clinical studies and appears to be a safe and effective EE program for tendinopathies rehabilitation; however it should be adjusted depending on the involved tendon. Although the excellent results point to EE as the treatment of choice, it is emphasized that this is only one of the components of the rehabilitation program. Biomechanical assessment, modification of risk factors, pain control strategies, activity modification, articular mobilization, massage and athlete re-education should also be considered and integrated [7]. It is essential to develop more studies with good methodological quality that compare the clinical and mechanical results of the different EE programs.

\section{References}

1. Frizziero A, Vittadini F, Fusco A, Giombini A, Masiero S (2016) Efficacy of eccentric exercise in lowerlimbtendinopathies in athletes. J Sports Med Phys Fitness 56(11): 1352-1358.

2. van der Plas A, de Jonge $S$, de Vos RJ, van der Heide HJ, Verhaar JA, et al. (2012) A 5-year follow-up study of Alfredson's heel-drop exercise programme in chronic midportion Achilles tendinopathy. Br J Sports Med 46(3): 214-218.

3. Gardin A, Movin T, Svensson L, Shalabi A (2010) The long-term clinical and MRI results following eccentric calf muscle training in chronic Achilles tendinosis. Skeletal Radiol 39(5): 435-442.

4. Knobloch K (2007) Eccentric training in Achilles tendinopathy: is it harmful to tendon microcirculation? Br J Sports Med 41(6): e2.

5. Langberg H, Ellingsgaard H, Madsen T, Jansson J, Magnusson SP, et al. (2007) Eccentric rehabilitation exercise increases peritendinous type I collagen synthesis in humans with Achilles tendinosis. Scand J Med Sci Sports 17(1): 61-66.

6. Jonsson P, Alfredson H (2005) Superior results with eccentric compared to concentric quadriceps training in patients with jumper's knee: a prospective randomised study. Br J Sports Med 39(11): 847-850.

7. Alfredson H, Pietila T, Jonsson P, Lorentzon R (1998) Heavyloadeccentriccalf muscle training for the treatment of chronic Achilles tendinosis. Am J Sports Med 26(3): 360-366. 

(c) (1) $\begin{aligned} & \text { Creative Commons Attribution } 4.0 \\ & \text { International License }\end{aligned}$

For possible submissions Click Here

Submit Article
RISM Im

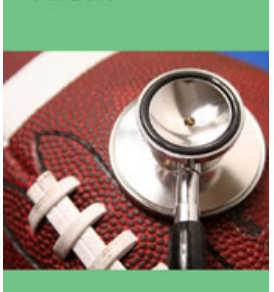

Research \& Investigations in Sports Medicine

\section{Benefits of Publishing with us}

- High-level peer review and editorial services

- Freely accessible online immediately upon publication

- Authors retain the copyright to their work

- Licensing it under a Creative Commons license

- Visibility through different online platforms 